Published in final edited form as:

Pediatr Clin North Am. 2015 December ; 62(6): 1523-1529. doi:10.1016/j.pcl.2015.07.013.

\title{
Mechanisms of Oral Tolerance
}

\author{
Scott P Commins, MD, PhD \\ Departments of Medicine and Pediatrics, University of Virginia School of Medicine, PO Box \\ 801355, Charlottesville, VA 22908, 434.924.5917 (ph), 434.924 .5779 (fax)
}

Scott P Commins: scottcommins@virginia.edu

\section{Synopsis}

Oral tolerance is an active process of local and systemic immune unresponsiveness to orally ingested antigens such as food. The gut immune system must balance responses to commensal bacteria (microbiome), innocuous antigens and pathogens. While it is clear that specialized populations immune cells and lymph nodes create a unique environment in the gut, there remains evidence to suggest that systemic effector sites are also critical to establishing and maintaining oral tolerance.

\section{Keywords}

mucosal; food allergy; tolerance; autoimmunity; oral antigen

\section{Introduction}

Oral tolerance is the active process by which the immune system does not respond to an orally administered antigen. The number of studies addressing oral tolerance in humans is surprisingly limited despite the extensive literature from murine models. In fact, animal models have largely been used to study both the mechanism of sensitization to food as well as the resulting allergic response from consuming a food allergen. Most available animal models of food allergy require an artificial sensitization method and may provide only limited insight into the sensitization phase of human food allergic disease. Thus, food allergy researchers have sought to develop an animal model that more closely mimics the sensitization of humans to food antigens. Until such a model, there may not be specific answers to the precise mechanisms that result in establishing oral tolerance or that lead to a break in tolerance. This review will provide an overview of some available animal models, comment on other disease states and relevant models as well as comment on possible future directions.

Disclosure: NIH grant recipient; UpToDate author

Publisher's Disclaimer: This is a PDF file of an unedited manuscript that has been accepted for publication. As a service to our customers we are providing this early version of the manuscript. The manuscript will undergo copyediting, typesetting, and review of the resulting proof before it is published in its final citable form. Please note that during the production process errors may be discovered which could affect the content, and all legal disclaimers that apply to the journal pertain. 


\section{Role of the gut immune system}

The gut-associated lymphoid tissue (GALT) is the largest immune system in the body ${ }^{1}$. Approximately $30 \mathrm{~kg}$ of food proteins reach the human intestine during a year, and 130-190 $\mathrm{g}$ of these proteins are absorbed daily in the gut ${ }^{2}$. The microbiota in the intestine is an additional major source of natural antigenic stimulation with a perhaps under-appreciated number of bacteria colonizing the human intestinal mucosa $\left(\sim 10^{12}\right.$ microorganisms / $\mathrm{g}$ of stool) ${ }^{3}$. The physiologic role of the GALT is the ingestion of dietary antigens in a manner that does not result in untoward immune reactions and protection of the organism from pathogens. This represents a careful balancing act as the mucosal barriers are thin and vulnerable to pathogenic infection. It should be noted that tolerance to food protein affects local and systemic immune responses, whereas tolerance to gut bacteria in the colon does not attenuate systemic responses. Despite these distinct and active processes, the GALT is primarily a tolerogenic environment.

The features of the gut immune system that are important participants in creating the tolerogenic environment have been studied and discussed ${ }^{4}$. Briefly, the inductive sites for immune responses in the gut are Peyer's patches and mesenteric lymph nodes (MLNs). MLNs develop distinct from Peyer's patches and peripheral lymph nodes and serve as a crossroads between the peripheral and mucosal recirculation pathways. To induce a mucosal immune response, an antigen must gain access to antigen-presenting cells by penetrating the mucus layer and then the intestinal epithelial cell barrier. Dendritic cells (DCs) themselves sample luminal contents by extending their processes through the epithelium without disruption of tight junctions 5,6 . Another important component of the GALT are intraepithelial lymphocytes (IELs), which serve to regulate intestinal homeostasis, maintain epithelial barrier function, respond to infection and regulate adaptive and innate immune responses ${ }^{7}$. The majority of IELs are CD8+ T cells, which express $\alpha \beta$ or $\gamma \delta \mathrm{T}$ cell receptors (TCRs). Of note, it has been reported that depletion of $\gamma \delta$ T cells impairs induction of oral tolerance ${ }^{8}$. Thus, the combination of commensals, T cells, and DCs set up a tolerogenic environment in the gut ${ }^{6,9,10}$. Major factors that condition the gut to be a tolerogenic environment are interleukin-10 (IL-10), retinoic acid, and transforming growth factor- $\beta$ (TGF- $\beta$ ), which serves as a switch factor for IgA, the predominant immunoglobulin of the gut ${ }^{11}$.

\section{Regulatory T cells}

It is now recognized that there are multiple mechanisms of oral tolerance, and one of the prime determinants is the dose of antigen fed ${ }^{4,12-19}$. Low doses favor the induction of regulatory $\mathrm{T}$ cell (Tregs), whereas higher doses favor the induction of anergy or deletion ${ }^{20}$. These mechanisms are not exclusive, especially at higher doses. One of the major mechanisms of oral tolerance is the induction of Treg cells, a process that is related to the gut DCs and linked to both TGF- $\beta$ and retinoic acid $10,17,21$. Specifically, it has been shown that mucosal DCs induce forkhead box P3 (Foxp3) Tregs via the production of TGF- $\beta$ but that concomitant retinoic acid signaling boosted this process ${ }^{22}$. In fact, all major classes of Tregs can be induced or activated by oral (mucosal) antigen ${ }^{23-27}$. Even CD8+ Tregs have been shown to play a role in oral tolerance ${ }^{28,29}$. Interestingly, CD8+ T cells have been 
shown to recall a tolerant or hyporesponsive phenotype following immune stimulation, suggesting that epigenetic mechanisms are in place to maintain tolerance ${ }^{30}$. As future work progresses, it remains to be elucidated whether similar mechanisms may account for failure of programmed reactive cells to maintain hyporesponsiveness following oral immunotherapy.

\section{Anergy}

$\mathrm{T}$ cell unresponsiveness or anergy is one of the primary mechanisms by which tolerance is maintained in self-reactive lymphocytes and anergy is induced in high-dose oral tolerance. The upregulation of anergy-associated genes is largely nuclear factor of activated T cells (NFAT) dependent ${ }^{31}$. Orally tolerized T cells can form conjugates with APCs but they are defective in immunologic synapse formation ${ }^{32}$. Similarly, T cells made anergic in vivo following oral antigen can inhibit the migration of responsive $\mathrm{T}$ cells in an antigenindependent fashion, indicating that hyporesponsive $\mathrm{T}$ cells have broad tolerogenic signals ${ }^{33}$. Using a murine model to examine the role of the thymus in high-dose oral tolerance, researchers found that thymectomized animals were not protected from autoimmune disease ${ }^{34}$. The thymus was actually found to be an important site for the development of CD4+CD25+ Tregs after oral antigen ${ }^{34}$. In fact, clonal deletion was found in the periphery but not the thymus - suggesting that high-dose oral tolerance not only induces deletion but may lead to CD4+CD25+ Tregs that resemble natural Foxp3+ Tregs ${ }^{34}$. These observations are in keeping with results from high-dose oral immunotherapy studies which have reported increased CD4+CD25+Foxp3+ Tregs in subjects with clinical hyporesponsiveness ${ }^{35}$.

\section{Lessons learned from oral anti-CD3}

The investigation of oral tolerance has classically involved the administration of oral antigen followed by challenge with same/similar antigen (albeit usually in an adjuvant) to demonstrate antigen-specific tolerance. One interesting experimental system that has been used to study T-cell function in oral tolerance is the use of TCR transgenic mice in which all T cells have a common TCR. Using such mice, Dr. Weiner and colleagues have investigated how oral administration of an antigen affected specific T-cell subsets. These investigators showed a dose-dependent induction of Tregs to the fed antigen ${ }^{36}$. In similar mice that have OVA specific TCR, high-dose oral administration of OVA led to deletion of Treg subsets ${ }^{37}$.

In order to translate these findings to humans, it first had to be known whether it was possible to trigger the TCR in wildtype mice in the gut and induce Tregs without using cognate antigen. Prior work had established that anti-CD3 binds to the $\varepsilon$ chain of the TCR and, given intravenously, deletes $\mathrm{T}$ cells and has been shown to be an effective treatment for type 1 diabetes in the non-obese diabetic mouse ${ }^{38}$. It was hypothesized that oral administration of anti-CD3 monoclonal antibody would replace the use of a cognate antigen to trigger the TCR and lead to induction of Tregs when given orally. Using an autoimmune encephalitis murine model, they found that oral anti-CD3 suppressed both clinical and pathologic features of the disease ${ }^{39}$. Notably, there was a dose effect observed with disease suppression by oral anti-CD3 seen at lower, but not higher doses ${ }^{39}$. The scientists suggested 
these findings were consistent with the classic paradigm of oral tolerance: induction of Tregs is seen at lower but not higher doses $19,20,37$. Potentially important for all researchers interested in oral tolerance, it demonstrated that induction of Tregs by oral anti-CD3 was not simply related to administering large amounts of antibody to overwhelm breakdown in the gut ${ }^{39}$. Also of significance was the finding that the Fc portion of anti-CD3 was not required, as anti-CD3 Fab'2 fragment was active orally and induced Tregs ${ }^{39}$. The effects of these and similar experiments raise the question whether it is more advantageous to induce antigenspecific versus antigen non-specific Tregs for the treatment of relevant diseases - an issue being addressed in ongoing trials in humans ${ }^{17}$.

\section{Site of tolerance to oral antigens: Gut vs Systemic}

One of the characteristic features of oral tolerance to soluble antigens is that it can involve the entire animal ${ }^{16}$. This is difficult to explain, however, as current thought focuses on anatomical compartmentalization within the mucosal immune system. In other words, antigen uptake and recognition is believed to be restricted to the GALT, MLNs, DCs and intestinal epithelial cells (discussed above), therefore limiting the effects to the intestinal mucosa. A possible explanation, and one that our lab and others are examining, is that orally administered antigens may disseminate systemically via blood and/or lymph ${ }^{40-43}$. In fact, earlier studies suggest that food protein can be detected in the blood of mice and humans soon after eating ${ }^{40,43}$. Furthermore, serum from protein-fed mice can induce antigenspecific tolerance in naive recipients, indicating the presence of "tolerogenic material" 44. This raises the important question of how and where an absorbed antigen can contribute to establishing oral tolerance.

One potential site is the liver. Administration of antigen directly into the portal vein, which drains blood from the intestine to the liver, is well known to induce antigen-specific tolerance ${ }^{45}$. Conversely, directing blood flow away from the liver by portocaval shunting prevents the induction of oral tolerance ${ }^{46,47}$. Liver has several features that could serve to promote tolerance (Table I). Antigen reaching beyond the liver into peripheral lymph nodes and spleen might be expected to induce tolerance in these sites, as it will be presented by resident DCs in the absence of co-stimulation, leading to the induction of anergy or Tregs ${ }^{16}$.

There is certainly evidence to the contrary, in that systemic dissemination of fed antigen is not important for oral tolerance. For example, transport of antigen from the lamina propria into the MLNs by CD103+ DCs was found to be crucial for inducing the systemic effects of oral tolerance ${ }^{48}$. Moreover, the chemokine receptor CCR7 is required for continual migration of DCs into draining lymph nodes and genetic deficiency in CCR7 prevented the recognition of fed antigen by $\mathrm{T}$ cells in the MLNs and impaired the induction of oral tolerance ${ }^{49,50}$. Other reports have also focused on MLNs having a central role in oral tolerance induction ${ }^{50,51}$. At this time it is unclear why there appears to be discordant findings about the relative roles of intestinal anatomic compartmentalization (e.g., GALT, MLNs) vs. more widespread dissemination of antigen (e.g., to the liver). Possible reasons for the discrepant results include 1) the concentration of antigen reaching the circulation, 2) nature of the antigen, 3) dose of antigen ingested, and 4) the microbiome of the animals $19,48,50$. 


\section{Conclusion}

Despite the extensive literature on the effectiveness of oral tolerance to treat diseases in animals this approach has yet to successfully translate to clinical treatment of IgE-mediated food allergy or even food hypersensitivity. With the advent of technologies such as mass cytometry and single-cell gene expression profiling applied to food allergy, we can only expect to reach a better understanding of cellular processes regulating oral tolerance. In the coming years, it will likely be time for the next phase of human studies of mucosal tolerance. The establishment of immunologic markers will provide the basis for dosing and measuring the effect of clinical trials. While one of the major goals of future immunotherapy might be to induce Tregs, food allergy researchers must also be cognizant of the role of IgEproducing cells and their location yet, to date, there are no specific methods to do this in vivo. The challenge is ours, therefore, to design or utilize clinical syndromes that can elucidate unknown aspects of oral tolerance and, specifically, breaks in tolerance that manifest as food allergy.

\section{Abbreviations}

$\begin{array}{ll}\text { DC } & \text { dendritic cell } \\ \text { Foxp3 } & \text { forkhead box P3 } \\ \text { GALT } & \text { gut-associated lymphoid tissue } \\ \text { IEL } & \text { intraepithelial lymphocyte } \\ \text { MLN } & \text { mesenteric lymph node } \\ \text { TCR } & \text { T cell receptor } \\ \text { TGF- } \beta & \text { transforming growth factor- } \beta \\ \text { Treg } & \text { regulatory T cell }\end{array}$

\section{Bibliography}

1. Moog F. The lining of the small intestine. Sci Am. 1981; 245(5):154-158. 160. 162 et passiom. [PubMed: 7330657]

2. Brandtzaeg P. Development and basic mechanisms of human gut immunity. Nutr Rev. 1998; 56(1 Pt 2):S5-18. [PubMed: 9481120]

3. Macfarlane GT, Macfarlane S. Human colonic microbiota: ecology, physiology and metabolic potential of intestinal bacteria. Scand J Gastroenterol Suppl. 1997; 222:3-9. [PubMed: 9145437]

4. Mowat AM. Anatomical basis of tolerance and immunity to intestinal antigens. Nat Rev Immunol. 2003; 3(4):331-341. [PubMed: 12669023]

5. Mowat AM, Donachie AM, Parker LA, et al. The role of dendritic cells in regulating mucosal immunity and tolerance. Novartis Found Symp. 2003; 252:291-302. discussion 302-295. [PubMed: 14609226]

6. Rescigno M. Functional specialization of antigen presenting cells in the gastrointestinal tract. Curr Opin Immunol. 2010; 22(1):131-136. [PubMed: 20060698]

7. Sheridan BS, Lefrançois L. Intraepithelial lymphocytes: to serve and protect. Curr Gastroenterol Rep. 2010; 12(6):513-521. [PubMed: 20890736]

8. Ke Y, Pearce K, Lake JP, Ziegler HK, Kapp JA. Gamma delta T lymphocytes regulate the induction and maintenance of oral tolerance. J Immunol. 1997; 158(8):3610-3618. [PubMed: 9103422] 
9. Strober W. The multifaceted influence of the mucosal microflora on mucosal dendritic cell responses. Immunity. 2009; 31(3):377-388. [PubMed: 19766081]

10. Izcue A, Coombes JL, Powrie F. Regulatory T cells suppress systemic and mucosal immune activation to control intestinal inflammation. Immunol Rev. 2006; 212:256-271. [PubMed: 16903919]

11. Li MO, Flavell RA. TGF-beta: a master of all T cell trades. Cell. 2008; 134(3):392-404. [PubMed: 18692464]

12. Mowat AM. Basic mechanisms and clinical implications of oral tolerance. Curr Opin Gastroenterol. 1999; 15(6):546-556. [PubMed: 17024005]

13. Vickery BP, Burks AW. Immunotherapy in the treatment of food allergy: focus on oral tolerance. Curr Opin Allergy Clin Immunol. 2009; 9(4):364-370. [PubMed: 19483615]

14. Peron JP, de Oliveira AP, Rizzo LV. It takes guts for tolerance: the phenomenon of oral tolerance and the regulation of autoimmune response. Autoimmun Rev. 2009; 9(1):1-4. [PubMed: 19224711]

15. Wang J, Toes RE. Mechanisms of oral tolerance revisited. Arthritis Res Ther. 2008; 10(2):108. [PubMed: 18466643]

16. Pabst O, Mowat AM. Oral tolerance to food protein. Mucosal Immunol. 2012; 5(3):232-239. [PubMed: 22318493]

17. Weiner HL, da Cunha AP, Quintana F, Wu H. Oral tolerance. Immunol Rev. 2011; 241(1):241259. [PubMed: 21488901]

18. Burks AW, Laubach S, Jones SM. Oral tolerance, food allergy, and immunotherapy: implications for future treatment. J Allergy Clin Immunol. 2008; 121(6):1344-1350. [PubMed: 18410959]

19. Chen YH, Weiner HL. Dose-dependent activation and deletion of antigen-specific T cells following oral tolerance. Ann N Y Acad Sci. 1996; 778:111-121. [PubMed: 8610965]

20. Friedman A, Weiner HL. Induction of anergy or active suppression following oral tolerance is determined by antigen dosage. Proc Natl Acad Sci U S A. 1994; 91(14):6688-6692. [PubMed: 8022835]

21. Dubois B, Joubert G, Gomez de Agüero M, Gouanvic M, Goubier A, Kaiserlian D. Sequential role of plasmacytoid dendritic cells and regulatory T cells in oral tolerance. Gastroenterology. 2009; 137(3):1019-1028. [PubMed: 19345221]

22. Mucida D, Park Y, Kim G, et al. Reciprocal TH17 and regulatory T cell differentiation mediated by retinoic acid. Science. 2007; 317(5835):256-260. [PubMed: 17569825]

23. Chen Y, Kuchroo VK, Inobe J, Hafler DA, Weiner HL. Regulatory T cell clones induced by oral tolerance: suppression of autoimmune encephalomyelitis. Science. 1994; 265(5176):1237-1240. [PubMed: 7520605]

24. Zhang ZJ, Davidson L, Eisenbarth G, Weiner HL. Suppression of diabetes in nonobese diabetic mice by oral administration of porcine insulin. Proc Natl Acad Sci U S A. 1991; 88(22):1025210256. [PubMed: 1946445]

25. Miller A, Lider O, Roberts AB, Sporn MB, Weiner HL. Suppressor T cells generated by oral tolerization to myelin basic protein suppress both in vitro and in vivo immune responses by the release of transforming growth factor beta after antigen-specific triggering. Proc Natl Acad Sci U S A. 1992; 89(1):421-425. [PubMed: 1370356]

26. Thorstenson KM, Khoruts A. Generation of anergic and potentially immunoregulatory CD25+CD4 T cells in vivo after induction of peripheral tolerance with intravenous or oral antigen. J Immunol. 2001; 167(1):188-195. [PubMed: 11418648]

27. Tsuji NM, Mizumachi K, Kurisaki J. Interleukin-10-secreting Peyer's patch cells are responsible for active suppression in low-dose oral tolerance. Immunology. 2001; 103(4):458-464. [PubMed: 11529936]

28. Chen Y, Inobe J, Weiner HL. Induction of oral tolerance to myelin basic protein in CD8-depleted mice: both CD4+ and CD8+ cells mediate active suppression. J Immunol. 1995; 155(2):910-916. [PubMed: 7541826]

29. Lider O, Santos LM, Lee CS, Higgins PJ, Weiner HL. Suppression of experimental autoimmune encephalomyelitis by oral administration of myelin basic protein. II. Suppression of disease and in 
vitro immune responses is mediated by antigen-specific CD8+ T lymphocytes. J Immunol. 1989; 142(3):748-752. [PubMed: 2464023]

30. Schietinger A, Delrow JJ, Basom RS, Blattman JN, Greenberg PD. Rescued tolerant CD8 T cells are preprogrammed to reestablish the tolerant state. Science. 2012; 335(6069):723-727. [PubMed: 22267581]

31. Macián F, García-Cózar F, Im SH, Horton HF, Byrne MC, Rao A. Transcriptional mechanisms underlying lymphocyte tolerance. Cell. 2002; 109(6):719-731. [PubMed: 12086671]

32. Ise W, Nakamura K, Shimizu N, et al. Orally tolerized T cells can form conjugates with APCs but are defective in immunological synapse formation. J Immunol. 2005; 175(2):829-838. [PubMed: 16002680]

33. Mirenda V, Millington O, Lechler RI, et al. Tolerant T cells display impaired trafficking ability. Eur J Immunol. 2005; 35(7):2146-2156. [PubMed: 15948215]

34. Song F, Guan Z, Gienapp IE, Shawler T, Benson J, Whitacre CC. The thymus plays a role in oral tolerance in experimental autoimmune encephalomyelitis. J Immunol. 2006; 177(3):1500-1509. [PubMed: 16849456]

35. Vickery BP, Scurlock AM, Kulis M, et al. Sustained unresponsiveness to peanut in subjects who have completed peanut oral immunotherapy. J Allergy Clin Immunol. 2014; 133(2):468-475. [PubMed: 24361082]

36. Chen Y, Inobe J, Kuchroo VK, Baron JL, Janeway CA, Weiner HL. Oral tolerance in myelin basic protein T-cell receptor transgenic mice: suppression of autoimmune encephalomyelitis and dosedependent induction of regulatory cells. Proc Natl Acad Sci U S A. 1996; 93(1):388-391. [PubMed: 8552644]

37. Chen Y, Inobe J, Marks R, Gonnella P, Kuchroo VK, Weiner HL. Peripheral deletion of antigenreactive T cells in oral tolerance. Nature. 1995; 376(6536):177-180. [PubMed: 7603570]

38. Chatenoud L, Bluestone JA. CD3-specific antibodies: a portal to the treatment of autoimmunity. Nat Rev Immunol. 2007; 7(8):622-632. [PubMed: 17641665]

39. Ochi H, Abraham M, Ishikawa H, et al. Oral CD3-specific antibody suppresses autoimmune encephalomyelitis by inducing CD4+ CD25- LAP+ T cells. Nat Med. 2006; 12(6):627-635. [PubMed: 16715091]

40. Husby S, Jensenius JC, Svehag SE. Passage of undegraded dietary antigen into the blood of healthy adults. Quantification, estimation of size distribution, and relation of uptake to levels of specific antibodies. Scand J Immunol. 1985; 22(1):83-92. [PubMed: 4023632]

41. Commins SP, James HR, Stevens W, et al. Delayed clinical and ex vivo response to mammalian meat in patients with IgE to galactose-alpha-1,3-galactose. J Allergy Clin Immunol. 2014; 134(1): 108-115. [PubMed: 24656556]

42. Warshaw AL, Walker WA. Intestinal absorption of intake antigenic protein. Surgery. 1974; 76(3): 495-499. [PubMed: 4852525]

43. Walker WA, Isselbacher KJ. Uptake and transport of macromolecules by the intestine. Possible role in clinical disorders. Gastroenterology. 1974; 67(3):531-550. [PubMed: 4137347]

44. Peng HJ, Turner MW, Strobel S. The generation of a 'tolerogen' after the ingestion of ovalbumin is time-dependent and unrelated to serum levels of immunoreactive antigen. Clin Exp Immunol. 1990; 81(3):510-515. [PubMed: 2397616]

45. Thomson AW, Knolle PA. Antigen-presenting cell function in the tolerogenic liver environment. Nat Rev Immunol. 2010; 10(11):753-766. [PubMed: 20972472]

46. Callery MP, Kamei T, Flye MW. The effect of portacaval shunt on delayed-hypersensitivity responses following antigen feeding. J Surg Res. 1989; 46(4):391-394. [PubMed: 2784839]

47. Yang R, Liu Q, Grosfeld JL, Pescovitz MD. Intestinal venous drainage through the liver is a prerequisite for oral tolerance induction. J Pediatr Surg. 1994; 29(8):1145-1148. [PubMed: 7965523]

48. Pabst O, Bernhardt G, Förster R. The impact of cell-bound antigen transport on mucosal tolerance induction. J Leukoc Biol. 2007; 82(4):795-800. [PubMed: 17565048]

49. Förster R, Davalos-Misslitz AC, Rot A. CCR7 and its ligands: balancing immunity and tolerance. Nat Rev Immunol. 2008; 8(5):362-371. [PubMed: 18379575] 
50. Worbs T, Bode U, Yan S, et al. Oral tolerance originates in the intestinal immune system and relies on antigen carriage by dendritic cells. J Exp Med. 2006; 203(3):519-527. [PubMed: 16533884]

51. Spahn TW, Weiner HL, Rennert PD, et al. Mesenteric lymph nodes are critical for the induction of high-dose oral tolerance in the absence of Peyer's patches. Eur J Immunol. 2002; 32(4):1109_ 1113. [PubMed: 11920578] 


\section{Key points}

- The gut has adapted a unique set of immune cells and sites to respond to antigens appropriately

- Numerous characteristics of antigens are important for the induction of oral tolerance

- Use of the oral route to establish tolerance holds promise for food-based antigens as well as other disease states 


\section{Table I}

Characteristics of hepatic function and structure that may favor tolerance

Liver endothelial cells sample circulating antigen and act as APCs that lead to tolerance ${ }^{45}$

Kupffer cells and conventional dendritic cells favor tolerance during antigen presentation 45

Plasmacytoid dendritic cells are abundant in the liver and support systemic tolerance ${ }^{21}$ 